\title{
Breast cancer and thoracic metastases: review of 119 patients
}

\author{
HARVEY KREISMAN, NORMAN WOLKOVE, HARRIET SCHWARTZ FINKELSTEIN, \\ CAROL COHEN, RICHARD MARGOLESE, HAROLD FRANK
}

From the Departments of Medicine and Surgery, Sir Mortimer B Davis Jewish General Hospital and McGill Cancer Centre, McGill University, Montreal, Quebec, Canada

ABSTRACT Review of the case notes of 660 patients with a diagnosis of breast cancer during a five-year period showed that in 119 cases there had been thoracic metastases. These were recorded as pleural or extrapleural metastases (79 patients), mediastinal tumour (46 patients), lymphangitic carcinoma (41 patients), pulmonary nodules (34 patients), and solitary pulmonary nodule (nine patients). Endobronchial metastases were present in seven patients and multiple pulmonary tumour emboli in two. The thorax was often the initial site of tumour recurrence. Most of these recurrences were present in several locations (intrathoracic or both intrathoracic and extrathoracic) simultaneously, facilitating the clinical diagnosis of metastatic breast cancer. Histopathological confirmation of metastasis was mandatory for the 10 patients who had a solitary intrathoracic abnormality without evidence of disease elsewhere. The median survival after diagnosis and treatment of a solitary thoracic metastasis was $42+$ months and three of 10 patients are currently in remission (at 44, 87, and 121 months). The small tumour burden and early diagnosis giving lead time may explain the long survival in this group of patients.

Breast cancer is the most common malignancy in women; $60-74 \%$ of patients dying of breast cancer have pulmonary metastases and the lung is the only site of metastasis in $21 \% .^{12}$ As many as $28 \%$ of lung metastases may be undetected before necropsy. ${ }^{2}$ These data from necropsy series, however, do not provide information about the clinical manifestations of breast cancer. This study was designed to find out the range of pulmonary metastases from breast cancer, the disease-free interval before their detection, and the prognosis after their discovery.

\section{Methods}

We reviewed the case records of all patients with a diagnosis of breast cancer (current or remote) at the Sir Mortimer B Davis Jewish General Hospital from 1 January 1975 to 31 December 1979. Almost all had their disease first diagnosed and received all their treatment at this institution. Records were scrutinised for mention of thoracic disease and

Address for reprint requests: Dr Harvey Kreisman, Division of Pulmonary Diseases, Department of Medicine, Sir Mortimer B Davis Jewish General Hospital, 3755 Côte Ste Catherine Road, Montreal, Quebec H3T 1E2, Canada. radiographs reported as abnormal were reviewed.

Thoracic metastases were said to be present on the basis of either pathological or radiographic criteria. Pathological confirmation of metastases was obtained at necropsy or by bronchoscopy, transthoracic needle biopsy, or thoracotomy. Malignant pleural effusions were diagnosed by pleural biopsy or cytological examination of pleural fluid. Patients who did not have histological confirmation of metastases were included only if their chest radiographs disclosed new pleural, parenchymal, or mediastinal abnormalities which persisted for at least two weeks and could not be explained by any concurrent illness. Skin or chest wall recurrence of tumour near the mastectomy site occurred commonly, but was not considered in this study as a thoracic manifestation of tumour. Thoracic skeletal metastases were usually part of diffuse bony disease and were therefore omitted. Patients with a second primary malignancy other than breast cancer were excluded from the study. When asynchronous primary tumours of the breast were present the metastases were considered to have arisen from the second tumour. Those patients with bilateral breast cancers were not included in the analysis of the laterality of metastatic pleural effusions. 
Confirmation and follow-up information was obtained by consultation with the patients' attending physicians. Most patients had been treated by or in consultation with one of the authors.

All operable tumours were treated by modified radical mastectomy or segmental mastectomy with axillary node dissection. All patients with affected lymph nodes received adjuvant therapy with L-phenylalanine mustard and 5-fluorouracil. On relapse patients were usually tested for oestrogen receptors and treated with either hormones or further chemotherapy as appropriate. This study did not examine the role of oestrogen receptor evaluation or specific treatments administered before and after detection of thoracic metastases.

\section{Results}

During 1975-9 there were 660 patients with a diagnosis of breast cancer on discharge from hospital. One hundred and nineteen patients had a thoracic metastasis from breast cancer. The features of these metastases are summarised in table 1.

Lung parenchymal metastases were seen in $\mathbf{8 0}$ patients. Lymphangitic carcinoma was the most common pattern of pulmonary parenchymal metastasis. Multiple nodules occurred almost four times as often as solitary nodules. Endobronchial metastases were detected by bronchoscopy or lung tomography in seven patients. Although lobar or segmental collapse prompted the suspicion of endobronchial metastasis, a mass was visualised on the routine radiograph of only two patients. Pulmonary arterial tumour emboli were diagnosed at necropsy in two patients. One had an 11-month history of progressive dyspnoea and cor pulmonale and the second had a syndrome suggesting acute pulmonary embolism.

Table 1 Patterns of thoracic metastases from breast cancer (119 patients)*

\begin{tabular}{lc}
\hline Metastases & No of \\
& patients \\
\hline Pulmonary $\dagger$ & 80 \\
Lymphangitic & 41 \\
Multiple nodules & 34 \\
Solitary nodule & 9 \\
Endobronchial metastasis & 7 \\
Tumour emboli & 2 \\
Alveolar metastasis & 1 \\
Pleural or extrapleural & 79 \\
Mediastinal or hilar & 46 \\
Pericardial metastasis & 9 \\
Myocardial metastasis & 2 \\
\hline
\end{tabular}

*More than one pattern of thoracic metastasis may be recorded for an individual.

tSome patients had more than one pattern of pulmonary metastasis.
Pleural metastasis. occurred in the ipsilateral hemithorax in 23 patients. In 19 others it was contralateral and in 22 patients bilateral.

Mediastinal tumour produced syndromes of hoarseness due to compression of the left recurrent laryngeal nerve (four patients), superior vena caval obstruction (two patients), phrenic nerve paralysis (four patients) and Horner's syndrome (1 patient). Respiratory failure occurred in two patients with upper airway obstruction related to tracheal compression by a mediastinal tumour. Two others had appreciable oesophageal compression and dysphagia.

Pericardial and myocardial metastases were usually necropsy findings and were not usually of clinical importance.

The thorax was often the initial site of tumour recurrence after surgery. The most common pattern observed was pleural metastasis, followed by mediastinal or hilar metastasis and/or pulmonary nodules (table 2). The initial thoracic recurrences were either multifocal or occurred simultaneously with other evidence of metastases. In only 10 instances was there a single focus of thoracic disease unaccompanied by other thoracic or extrathoracic metastatic disease. Tumour emboli, alveolar metastasis and pericardial and myocardial metastases were never the first location of metastasis from breast cancer.

The interval between the first diagnosis of breast cancer and the detection of an initial thoracic meta:stasis varied considerably. Although most recurrences appeared within five years, 13 patients first showed metastatic disease in the thorax 5-10 years after mastectomy and 12 others had an initial thoracic metastasis after an interval greater than 10 years. Thus $35 \%$ of all initial thoracic metastases had a disease-free interval greater than five years and in $17 \%$ it was longer than 10 years. Although no particular site was strikingly associated with a long disease-free interval, five of the 12 patients with

Table 2 Initial thoracic metastases in breast cancer

\begin{tabular}{lll}
\hline Site & $\begin{array}{l}\text { No of } \\
\text { patients* }\end{array}$ & $\begin{array}{l}\text { Initial } \\
\text { recurrencest }\end{array}$ \\
\hline Lymphangitic & 41 & $11(27)$ \\
Pulmonary nodules & 43 & $23(53)$ \\
Endobronchial & 7 & $2(29)$ \\
Pleural or extrapleural & 79 & $23(29)$ \\
Mediastinum or hilum & 46 & $12(26)$ \\
\hline
\end{tabular}

* Number of patients having a metastasis at the specified site at any time during the course of their illness.

†The first of any metastases in the illness. With the exception of 10 patients (see table 4), these were simultaneously present in multiple intrathoracic or intrathoracic and extrathoracic sites. Numbers in parentheses represent percentages of metastases at each site that were initial recurrences. 
Table 3 Survival ${ }^{*}$ after thoracic metastases from breast cancer according to site affected

\begin{tabular}{|c|c|c|c|c|c|c|c|c|}
\hline \multirow[t]{2}{*}{. } & \multicolumn{4}{|c|}{ Initial metastasis } & \multicolumn{4}{|c|}{ Subsequent metastasis } \\
\hline & $0 m^{\dagger}$ & $1-12 m$ & $13-24 m$ & $>24 m$ & $0 m^{\dagger}$ & $1-12 m$ & $13-24 m$ & $>24 m$ \\
\hline $\begin{array}{l}\text { Lymphangitic } \\
\text { Pulmonary nodules } \\
\text { Pleural or extrapleural } \\
\text { Mediastinum or hilum }\end{array}$ & $\begin{array}{l}0 \\
0 \\
1 \\
1\end{array}$ & $\begin{array}{l}2 \\
5 \\
5 \\
2\end{array}$ & $\begin{array}{r}5 \\
10 \\
5 \\
4\end{array}$ & $\begin{array}{r}3 \\
8 \\
10 \\
5\end{array}$ & $\begin{array}{r}9 \\
2 \\
11 \\
8\end{array}$ & $\begin{array}{l}13 \\
11 \\
26 \\
13\end{array}$ & $\begin{array}{l}5 \\
3 \\
8 \\
5\end{array}$ & $\begin{array}{r}1 \\
4 \\
10 \\
5\end{array}$ \\
\hline
\end{tabular}

*Survival data not available for three cases of lymphangitic carcinoma (one initial), three of pleural or extrapleural metastasis (two initial), and three of mediastinal or hilar disease (none initial).

†Initial diagnosis of metastatic focus at postmortem examination.

Table 4 Solitary ịitial thoracic metastases in breast cancer: clinical course

\begin{tabular}{|c|c|c|c|c|c|}
\hline Site & $\begin{array}{l}\text { Clinical } \\
\text { features }\end{array}$ & $\begin{array}{l}\text { Disease-free } \\
\text { interval }(m)\end{array}$ & $\begin{array}{l}\text { Method of } \\
\text { diagnosis }\end{array}$ & $\begin{array}{l}\text { Duration of } \\
\text { remission }(\mathrm{m})\end{array}$ & $\begin{array}{l}\text { Survival } \dagger \\
\text { (m) }\end{array}$ \\
\hline Mediastinum & $\begin{array}{l}\text { Phrenic paralysis } \\
\text { Lymphadenopathy }\end{array}$ & $\begin{array}{l}60 \\
68\end{array}$ & $\begin{array}{l}\text { Mediastinotomy } \\
\text { Mediastinotomy }\end{array}$ & $\begin{array}{r}7 \\
39\end{array}$ & $\begin{array}{l}22 \\
39\end{array}$ \\
\hline \multirow[t]{4}{*}{ Pleura } & Pain (ipsilateral) & 57 & Biopsy & 5 & $24 \ddagger$ \\
\hline & Pain (ipsilateral) & 35 & Biopsy & 3 & 9 \\
\hline & Dyspnoea & 50 & Biopsy & $87^{*}$ & $87 \ddagger$ \\
\hline & Dyspnoea & 153 & Biopsy & 52 & $54 \ddagger$ \\
\hline \multirow{5}{*}{ Solitary nodule } & Routine radiograph & 49 & Excision & $44^{*}$ & $44 \ddagger$ \\
\hline & Routine radiograph & 60 & Lobectomy & $121^{*}$ & $121 \ddagger$ \\
\hline & Routine radiograph & 147 & Pneumonectomy & 41 & 53 \\
\hline & Routine radiograph & 10 & Biopsy & 9 & 10 \\
\hline & & Median 59 & & Median 40 & Median 42+ \\
\hline
\end{tabular}

${ }^{*}$ Currently in remission

† Survival after diagnosis of initial thoracic metastasis.

$\ddagger$ Living.

intervals greater than 10 years had pleural metastases.

In table 3 the survival times of patients with thoracic metastases are grouped according to whether they were the first sign of tumour dissemination in the body (initial metastases) or whether they were recognised only after other intrathoracic or extrathoracic sites had been discovered (subsequent metastases).

Analysis of survival based on sites of metastases showed a constant pattern with the exception of pleural metastases. Survival was greater than 12 months in $75 \%$ of all patients with initial thoracic metastases. In contrast, only $31 \%$ of all patients with subsequent metastases lived more than 12 months. Thirty-nine per cent of those with initial metastases and $15 \%$ with subsequent metastases survived two years.

Pleural or extrapleural metastases seemed to be associated with a longer survival time, particularly if they were the sites of initial metastases. Ten of 21 patients with initial pleural metastases lived longer than two years. On the other hand, those with lymphangitic metastases, which usually appeared after other metastases, had the shortest survival. Only four of 38 patients with lymphangitic metastases lived longer than two years.

The clinical course of the 10 patients with a soli- tary initial focus of metastatic disease confined to the thorax is shown in table 4 . The diagnosis was suspected because of thoracic symptoms and a radiographic abnormality or because of an abnormal routine radiograph. The median disease-free interval was 59 months. A definitive diagnosis required examination of a biopsy or surgical specimen.

After diagnosis of a solitary intrathoracic metastasis (10 patients), treatment produced a median remission of 40 months (range 3-121 months). Three patients are in remission 44,87 , and 121 months after diagnosis of the thoracic metastasis. The median survival after treatment of an initial solitary thoracic metastasis was $42+$ months (range 9-121+ months). Two patients are alive with disease and five have died of metastatic breast cancer.

The four patients who underwent resection of solitary pulmonary nodular metastases had remissions of nine, 41, 44, and 121 months. Two of these patients are currently disease free 44 and 121 months after surgery. Both patients who relapsed after surgery had recurrence of tumour within the lung.

\section{Discussion}

This study illustrates the range of thoracic metastases from breast cancer. The diagnosis of metastatic 
thoracic disease is often suspected because of a previous diagnosis of metastatic cancer, the simultaneous appearance of several intrathoracic foci, or the appearance of both thoracic and systemic disease. When a single focus of initial metastasis is present, prompt diagnosis and treatment may produce a complete response and prolonged survival. The 10 patients with a single focus of initial metastasis have a median survival of over 42 months, with three patients currently in remission.

Although most initial thoracic metastases occurred within five years, $18 \%$ occurred five to 10 years after diagnosis and $17 \%$ of initial thoracic metastases occurred more than 10 years after diagnosis. The longest disease-free interval before an initial metastasis was 16 years. Occasionally the thoracic metastasis is the only evidence of breast cancer and the primary lesion is detected after resection of the metastasis. $^{3}$

Lymphangitic metastasis was the most frequently observed pulmonary parenchymal manifestation. Although lymphangitic metastasis may be suspected from the history of progressive dyspnoea with or without a non-productive cough, and diffuse reticular infiltrates on the chest radiograph, a definitive diagnosis requires histopathological confirmation. The differential diagnosis of lymphangitic carcinoma includes opportunistic infection and drug-induced lung disease. Patients with suspected opportunistic infection underwent lung biopsy, but infection may have been unrecognised in those who were terminally ill and considered to have lymphangitic carcinoma by clinical assessment. Cyclophosphamide and methotrexate are also capable of producing diffuse lung disease ${ }^{45}$ and may have been responsible for some cases of interstitial disease attributed to lymphangitic carcinoma.

Although endobronchial metastasis has been thought to be an unusual feature of breast cancer, ${ }^{67}$ we documented it in seven patients. Furthermore, breast cancer may be the most common cause of endobronchial metastasis. ${ }^{8}$ The routine use of bronchoscopy may bring to light a higher-than expected incidence of endobronchial metastasis. ${ }^{9}$

The clinical syndromes usually associated with mediastinal extension of lung cancer ${ }^{10}$ may be present in patients with metastatic breast cancer. In addition, syndromes related to oesophageal ${ }^{11} 12$ and tracheal compression were observed. Endotracheal mucosal metastasis ${ }^{8}$ was not observed in this series.

Pericardial and myocardial metastases are rarely suspected before death ${ }^{2}$ and our patients with spread of tumour to these sites only had the diagnosis confirmed just before death or at postmortem examination. The possibility of metastasis to these organs should be considered when unexplained car- diac disease appears in a patient with breast cancer.

Pleural metastasis from breast cancer has generally been associated with a poor prognosis. Fentiman et al reported a median survival of 13 months $^{13}$ and in another series $95 \%$ of patients with a malignant pleural effusion (from any primary tumour) were dead within 12 months. ${ }^{14}$ In our series pleural metastasis was associated with a longer survival time after diagnosis than were either pulmonary or mediastinal metastases. This better prognosis may be related to disease in bone with extension into adjacent pleura in an appreciable number of cases. This route of tumour spread may have a different prognosis from the group with pleural effusion related to haematogenous tumour deposits of lymphatic obstruction.

Ten patients in this series had a solitary focus of metastasis confined to the thorax, most commonly a pleural effusion or a solitary pulmonary nodule. Since extrathoracic metastases were absent, pathological confirmation was required. Treatment of the single metastasis was often associated with long survival and even complete remission. Two of the three complete remissions occurred in patients with solitary pulmonary nodules. Others have also noted the favourable prognosis after surgery for solitary metastasis from breast carcinoma. ${ }^{15-17}$ Two of four patients with solitary pulmonary nodules relapsed with metastases within the lung after surgery. Small metastatic foci, undetectable at the time of surgery, amy be responsible for subsequent relapse. The use of preoperative computed tomography may disclose these otherwise undetectable areas of disease ${ }^{18}$ and therefore predict which patients are least likely to benefit from surgery.

The slow progression of tumour (and three complete remissions) in the group with a single detectable metastatic focus may be related to the small tumour burden and hence increased efficacy of either chemotherapy or hormonal treatment. ${ }^{19}$ Alternatively, the long survival in this group may be explained by the long lead time and earlier diagnosis of a metastatic focus during the natural history of a slow-growing tumour. The problem of the initial solitary thoracic metastasis is a diagnostic challenge requiring histopathological confirmation. After diagnosis treatment may produce a sustained remission of disease.

This work was supported in part by the Giuseppe Saputo Endowment Fund for Lung Cancer Research. We thank Mrs Anita Ilieff for help in preparation of the manuscript. 


\section{References}

${ }^{1}$ Weiss L, Gilbert HA. Pulmonary metastasis. Vol 1. Boston, Massachusetts, GK Hall: 1978.

${ }^{2}$ Hagemeister FB, Buzdar AU, Luna MA, Blumenschein GR. Causes of death in breast cancer: a clinicopathologic study. Cancer 1980;46:162-7.

${ }^{3}$ Shepherd MP. Thoracic metastases. Thorax 1982;37:366-70.

4 Lisbona A, Schwartz J, Lachance C, Frànk H, Palayew MJ. Methotrexate-induced pulmonary disease. J Can Assoc Radiol 1973;24:215-20.

${ }^{5}$ Lippmann M. Pulmonary reactions to drugs. Med Clin North Am 1977;61:1353-67.

- DeBeer RA, Garcia RL, Alexander SC. Endobronchial metastasis from cancer of the breast. Chest 1978;73:94-6.

${ }^{7}$ Daskalakis MK. Endobronchial metastasis from breast carcinoma. Int Surg 1981;66:165-6.

${ }^{8}$ Baumgartner WA, Mark JBD. Metastatic malignancies from distant sites to the tracheobronchial tree. $J$ Thorac Cardiovasc Surg 1980;79:499-503.

9 Shepherd MA. Endobronchial metastatic disease. Thorax 1982;37:362-5.

${ }^{10}$ Margolese RG, Kreisman H, Wolkove H, Cohen C, Frank H. Recent advances in management of lung cancer. In: MacLean LD, ed. Advances in surgery. Chicago: Year Book Medical Publishers, 1981: 189 221 .
1 Vansant JH, Davis RK. Esophageal obstruction secondary to mediastinal metastasis from breast carcinoma. Chest 1971;60:93-5.

12 Polk HC, Camp FA, Walker AW. Dysphagia and esophageal stenosis. Cancer 1967;20:2002-7.

${ }^{13}$ Fentiman IS, Millis R, Sexton S, Hayward JL. Pleural effusion in breast cancer: a review of 105 cases. Cancer 1981;47:2087-92.

14 Chernow B, Sahn SA. Carcinomatous involvement of the pleura. Am J Med 1977;63:695-702.

15 Vincent RG, Choksi LB. Surgical resection of the solitary pulmonary metastasis. In: Weiss L, Gilbert HA, eds. Pulmonary metastasis. Vol 1. Boston, Massachusetts: G K Hall, 1978.

${ }^{16}$ McCormack PM, Bains MS, Beattie EJ, Martini N. Pulmonary resection in metastatic carcinoma. Chest 1978;73:163-6.

${ }_{17}$ Saegesser F. Traitement chirurgical des foyers ronds pulmonaires décelés chez un cancereux et six cancereuses du sein. Helv Chir Acta 1977;44:647-61.

${ }^{18}$ Chang AE, Schaner EG, Conkle DM, Flye MW, Doppman JL, Rosenberg SA. Evaluation of computed tomography in the detection of pulmonary metastases: a prospective study. Cancer 1979;43:913-6.

${ }^{19}$ Legha SS, Buzdar AU, Smith TL et al. Complete remissions in metastatic breast cancer treated with combination drug therapy. Ann Intern Med 1979;91:84752. 